\title{
UNDERGRADUATE STUDIES IN PHYSICAL EDUCATION IN STUDENTS' OPINION Undergraduate studies in physical education
} KRYSTYNA BUCHTA ${ }^{1}$, TOMASZ LISICKI ${ }^{2}$

\author{
1 The Josef Pilsudski University of Physical Education in Warsaw, Faculty of Physical Education \\ and Sport in Biała Podlaska, Department of Marketing and Statistics \\ 2 University of Zielona Góra, Chair of Physical Education
}

\author{
Mailing address: Krystyna Buchta, Faculty of Physical Education and Sport, 2 Akademicka Street, \\ 21-500 Biała Podlaska, tel.: +48 83 3428784, fax: +48 83 3428800, e-mail: krystyna.buchta@awf-bp.edu.pl
}

\begin{abstract}
Introduction. The aim of this study was to assess the effects of the undergraduate studies in physical education at the Academy of Physical Education and Sport (APE\&S) in Gdańsk and Faculty of Physical Education and Sport (FPE\&S) in Biała Podlaska of the Warsaw University of Physical Education (UPE). Material and methods. The study included a total of 247 last semester students of full-time education course. The paper uses a method of diagnostic survey with auditorium questionnaire technique. Referring to the provisions of the Bologna Declaration on the implementation of two-degree studies and based on students' opinions, research was conducted in form of comparative studies. Evaluation included circumstances of the choice of study, conditions of study, expectations of respondents to the education and degree of their implementation. Results. Subjects taking physical education studies are mainly motivated by interests. They hoped to gain knowledge and skills for further education and professional competence. They highly appreciated the degree of fulfilment of expectations in this regard. Conclusions. There was a large convergence of views presented by students of both universities on the education process and its outcomes.
\end{abstract}

Key words: Bologna process, physical education, undergraduate studies, expectations, education results

\section{Introduction}

With the signing of the Bologna Declaration by Poland, a number of activities related to the creation of the European Higher Education Area have been taken. The Bologna reform, among others, assumed development of a common European strategy allowing for creation of conditions for greater mobility of citizens, adaptation of the education system to labour market needs, improving the employment rate of graduates, and thus increasing the attractiveness and improving the competitiveness of higher education in Europe [1]. One of the system solutions aimed to achieve the assumed goals of the Bologna reform was the introduction of two-stage education model. First degree (undergraduate), known as licentiate, is intended to guarantee getting the appropriate level of knowledge and professional skills, allowing for work in any European company, or to continue education at the graduate level. The second stage of education (graduate, master) is to develop and strengthen the professional competence, and to allow for the acquisition of knowledge to undertake e.g. PhD studies [2].

The transition from a uniform graduate studies model to a two-stage education system produces a number of discussions, and the positive aspects include, among others, greater flexibility allowing to complete education after the first degree and taking a job or to stop education for a while, and then continue it in the second degree. At the same time such a system is to encourage the mobility of students between the universities, as well as the majors, giving the possibility to transfer the existing attainments in the field of education from one country to another. It was assumed that increased mobility of students will influence the competence in the quality of education between the universities, which is an essential element in enhancing the 
attractiveness and improvement of the competitive position of higher education in Europe $[3,4,5,6,7]$.

Against the background of the Bologna settlements related to the implementation of multi-stage structure of education, the present study was aimed at evaluation of the progress and outcomes of undergraduate degree studies in physical education in Gdańsk APE\&S and FPE\&S of Warsaw UPE in Biała Podlaska.

The aim of the study was to discover the circumstances of the choice of study, expectations of respondents to the education and degree of their implementation, and evaluation of the conditions of study at surveyed universities.

\section{Material and methods}

The study covered a total of 247 last semester of fulltime $1^{\text {st }}$ degree students, majoring in physical education, including 112 from FPE\&S of Warsaw UPE in Biała Podlaska and 135 students from APE\&S in Gdańsk.

The study was conducted in the academic year $2008 / 2009$. The empirical material was collected by the method of diagnostic survey with auditorium questionnaire technique.

Questionnaire addressed to students completing undergraduate studies contained a block of issues such as providing answers to the following questions:

1. What sources did the respondents use when looking for information about studying in UPE?

2. What factors have decided on taking physical education?

3. What expectations of the university and field of study did the respondent have and how do they assess their implementation?

4. How do respondents assess the conditions of studying?

5. What further educational and vocational plans do subjects completing their undergraduate studies have?

Based on feedback from students of both universities comparative analyses were performed, using t-Student's test and chi-square test (difference with significance level of $\mathrm{p}<0.05$ was taken as statistically significant).

\section{Results}

\section{Characteristics of the subjects}

Analysis of the collected material revealed the presence of significant differences in socio-demographic structure of the students from both universities. Among adolescents in Gdańsk APE\&S, more often than it was reported in the tests on FPE\&S in Biala Podlaska, there were women
( $63 \%$ vs. $42 \%$ ), urban dwellers ( $87 \%$ vs. $63 \%$ ), persons declaring a good financial situation ( $50 \%$ vs. $37 \%$ ), as well as working professionally at the time of study ( $24 \%$ vs. $9 \%)$. Respondents were also differentiated by the level of formal competence measured by the average study rating, and among the students of APE\&S a higher percentage of good students was reported, with an average in the range of 4.14.5 ( $42 \%$ vs. $21 \%)$.

\section{Background of choosing physical education}

Selecting a university is a very important decision for a young man, in fact it affects the fate of his career and life. Knowledge of the circumstances and factors determining the choice of universities and educational direction is crucial also for the university, as it allows to effectively manage promotional activities, by acting indirectly on this process [8]. From this perspective, it was important to know e.g. sources of information about the college, which the respondents most commonly used.

Analyzing the responses of students, it should be noted that the dominant role was played by the opinions of friends, acquaintances, and most often such suggestions motivated students of FPE\&S (77\% vs. 62\%). Less frequently they pointed to the Internet, as a primary source of data on education ( $30 \%$ APE\&S students and $40 \%$ of FPE\&S). In the case of nearly every third student university of Gdańsk, and just one in ten of the Biała Podlaska faculty, the Handbook of Studies was used (differences significant, $\mathrm{p}<0.05)$. A similar, low percentage of respondents participated in events organized by the university Open Days.

Due to the fact that the competent and properly motivated choice decided on the course of study, and consequently about the "quality of a graduate", an attempt to understand the factors influencing the decisions of this kind in the choice of undergraduate degree in physical education was made.

The study results revealed that the selection of university and educational direction by the subjects depended on the combination of various factors, among which there dominated the interest in the subject of study, more often declared by the young people of APE\&S ( $84 \%$ vs. $68 \%$ ). Among the reasons for undertaking studies, an important factor indicated especially by students of FPE\&S, was also the reputation of the university ( $43 \%$ vs. $25 \%)$. Only one in three studying in FPE\&S and even slightly lower percentage of respondents from Gdańsk University, were guided in their selection by a desire to study the profession in line with the education major. In addition, every fourth respondent from APE\&S and only every eighth student undertaking studies in FPE\&S hoped to develop his own sports ca- 
reer (difference statistically significant). The convenient location of university more often determined the choice of education for students from Biała Podlaska (27\%) than that reported among the students of Gdańsk Academy (8\%) (Fig. 1).

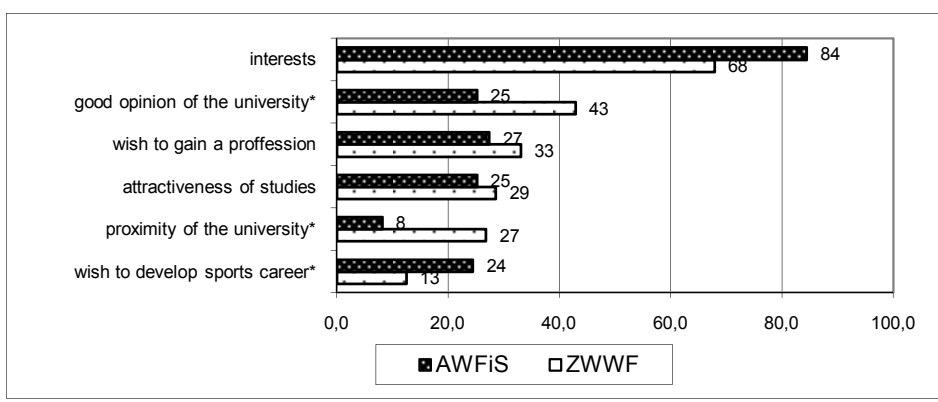

* - statistically relevant differences; $\mathrm{p}<0.05$

Figure 1. Factors deciding on taking of studies by the respondents (\%)

\section{Expectations of the respondents related to the studies and degree of their implementation}

Respondents were asked to indicate on a scale 1-5 (5the maximum number of points) the expectations, which they have associated with the completion of their studies. Of the eleven features (factors) that have been evaluated, the most important were: the general intellectual development, teamwork, preparation for further education. They also hoped for preparation for work in schools and other institutions of physical culture, therefore the knowledge and skills of a specific professional profile. Arithmetic averages of these expectations were at the level of 4.0 and above according to a five-point scale. Also a good preparation for the self-education was expected. It is characteristic that the statements of students of both universities maintained a similar hierarchy in this respect.

The least important in taking the major of study by the respondents proved to be the managerial preparation, and the students of Gdańsk Academy expected much lower level of such competence (2.9 points) than FPE\&S students (3.5 points according to a five-point scale). In addition, students of APE\&S at just a sufficient level expected preparation for self-employment in business and computer courses, while expectations of the students of Biała Podlaska were significantly higher and amounted to respectively 3.6 and 3.8 points (Fig. 2 ).

The study also sought to determine the degree of individual mastering of competence, included in the study. Comparing students' opinions about the level of knowledge and skills acquired in the educational process with the expectations in this regard, it was found that the level of any of the assessed items was significantly lower than expected. The largest discrepancies (relative to expectations) referred to mastery of foreign languages, which clearly appeared particularly acute among students of Gdańsk Academy (difference 1.6 points vs. 0.9 points of FPE\&S youth). The relatively large differences (about 1 point) were noted in preparation to launch one's own business, implement plans related to sport career development by the respondents, as well as the overall intellectual development and managerial preparation. In turn, the level of directional competences allowing for work in education or in physical culture institutions was most in line with expectations. There was a close compliance in preparation for selfeducation and team skills (Fig. 3).

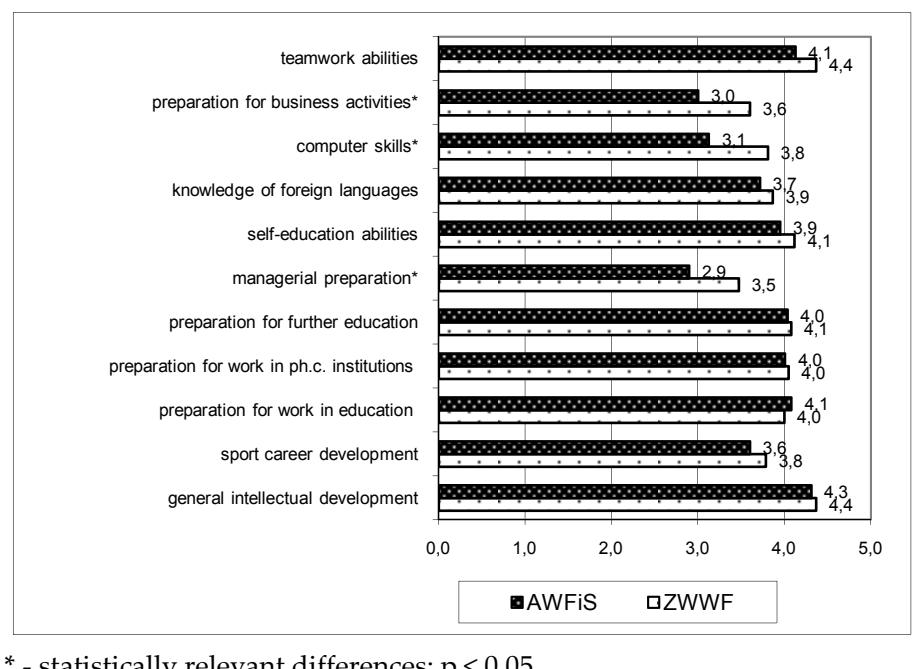

* - statistically relevant differences; $p<0.05$

Figure 2. Expectations of the respondents toward the universities

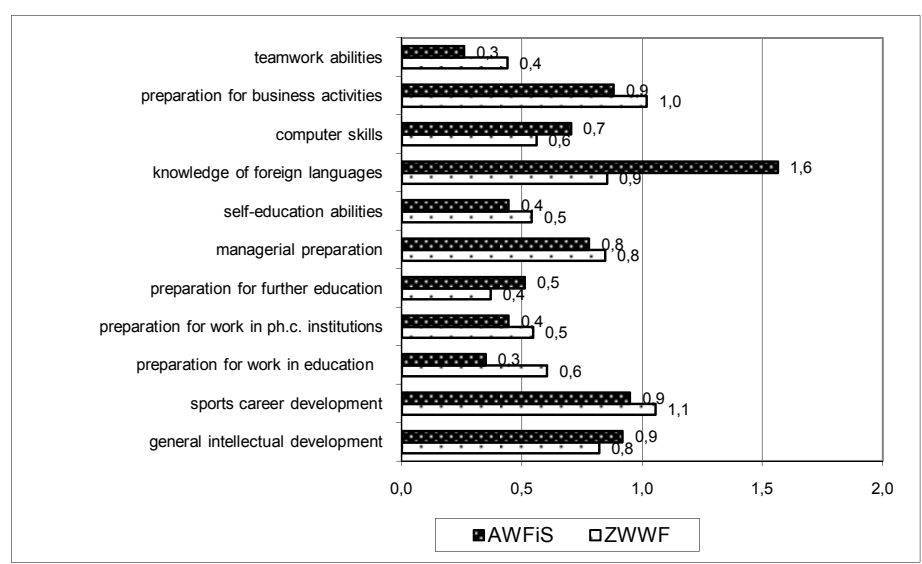

Figure 3. Discrepancies between the expectations toward the universities and their implementation (competence gap) 
Students' opinions about the selected elements

\section{of University operations}

The quality of education depends largely on the study conditions created by the university, hence the subject of analysis were also investigated about the opinions of students' of different backgrounds on some aspects of the university functioning (expressed in a five-point scale).

College reality as seen through the prism of the experience of both groups of respondents was best assessed on items such as the availability of literature, the atmosphere prevailing in university and institution housing conditions (at the level of good reviews.) In addition, students of Biała Podlaska significantly appreciated better the laboratory equipment and the availability of teachers than those of Gdańsk. Significant differences in the opinions of respondents also included the access to computers and the Internet in schools, but these items were better in the assessment of APE\&S students. According to respondents, the real weaknesses of both universities involve the timetables - rated at less than satisfactory (Fig. 4).

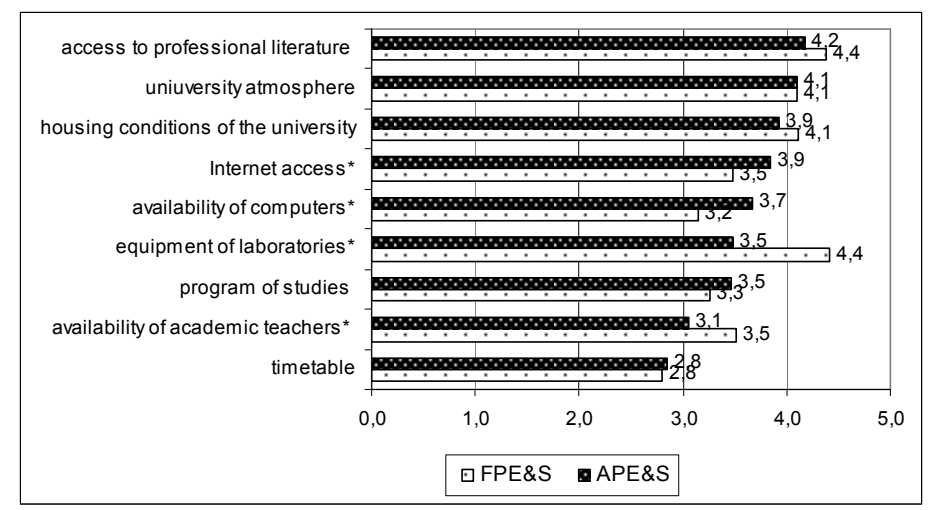

* - statistically relevant differences; $\mathrm{p}<0.05$

Figure 4. Assessment of studying conditions by the respondents scale 1-5 (5- max)

The presentation of respondents' opinions on the study conditions is supplemented by the information on satisfaction with the selection and course of study. Analysis of the distribution of statements by representatives of both universities showed great similarity here, and the structure was dominated by the percentage of "rather satisfied" indications (about $2 / 3$ of respondents), while every fifth respondent described himself as definitely happy with the choice of educational direction and course of study. Confirmation of positive feedback in this regard included statements of nearly $90 \%$ of respondents who opted for possible re-selection of physical education studies.
Educational-professional plans of the respondents after completion of undergraduate studies

Analysis of the collected material showed that the majority of respondents plans to take the second stage studies, although more such declarations were made by the students of Biała Podlaska (71\%) than Gdańsk facility (59\%), and nearly one in three respondent planned to work after completion of undergraduate studies and take further education in the form of courses or training. In addition, every third respondent in APE\&S declared to take up $2^{\text {nd }}$ degree studies while working. Only $2 \%$ of the respondents from FPE\&S students reported that eventuality, which seems to confirm the correctness of the thesis of the better opportunities for the development of young people and at the same time job opportunities in large urban areas as compared to smaller towns [9].

\section{Discussion}

The Act of September 12, 1990 on higher education, allows higher education institutions for substantial autonomy in the process of education in the same areas of study. Thus, both recruitment and selection procedures for students, as well as existing programs and plans of study and requirements for their implementation can be quite varied in corresponding universities. Consequently, the same diplomas do not have to be accompanied by the same competence of graduates.

Attempt to look at how in view of substantial autonomy to universities students of FPE\&S of Warsaw UPE and Gdańsk APE\&S evaluate progress and outcomes of undergraduate degree in physical education, showed significant similarity of opinions expressed in this regard.

A broad convergence of views has already been examined when trying to see the most important determinants of educational decisions, because according to the declaration of respondents, undergraduate studies were taken in both cases guided mainly by the interest in the chosen field of knowledge. The pro-professional motives, as well as the reputation and attractiveness of the university faculty took further positions in the ranking of the factors taken into consideration by the representatives of the communities surveyed. The results of this phase of the study showed, however, that the advantageous location of universities more often made an important argument when making the choice by youth of Biała Podlaska, which leads to the conclusion regarding the performance of additional functions relevant to the environmental (local) needs by educational establishments located in smaller towns [10]. 
For both groups of respondents there was also reported a similar pattern of expectations for the undergraduate level of studies in terms of selected competencies. In the hierarchy of the importance of characteristics undergoing assessment of students, the aims of acquiring knowledge and skills to further education proved to be the most important. Primarily the general intellectual development, as well as skills in teamwork and self-education were calculated. In the opinion of respondents, it was also important to gain further competence. The least important, especially for students of Gdańsk Academy, was to obtain some general competencies such as: managerial preparation and good preparation to undertake an independent economic activity. Surprisingly low proved to be the expectations of young people of this university for skills in computer operation.

Analogy between the opinions of students of both communities were also observed in the assessment of learning outcomes, as measured by the degree of satisfaction with the expectations of students. The results of the analysis showed that in both schools similar efficacy of education was achieved, with the highest rates related to selected organizational skills (teamwork), and the direction competency. Analyzing the competence gap in the span of each of the assessed elements was further found that the most consistent with the expectations turned out to be here the preparation for taking further training and preparation for professional work, which is consistent with the idea of undergraduate studies [7]. The greatest discrepancies were observed in knowledge of foreign languages. Meanwhile, if education is to create a multi-stage opportunities for greater mobility of students, allowing the free transfer of the existing attainments in the field of education from one country to another, such skills seem to be crucial.

In a relatively low degree both universities have responded to the expectations of the respondents in preparing to take their own business. It is a negative phenomenon, particularly in the context of an increasingly widespread taking up of work by the graduates of these institutions outside the education sector $[11,12,13,14]$ and the findings of Bologna on the need for universities to tailor their offerings to the needs of labour markets - national and European $[6,15,16]$. Self-employment may constitute an alternative to the declining demand for physical education teachers. In this context, and in the diagnosis of low managerial competence test, Jaworski's offer seems reasonable combining physical education studies of teaching with, among others, the training of managers of physical culture [13]. Free market law more often place a physical education teacher in a situation requiring typically managerial activi- ties, i.e.: motivating the players to a systematic effort, organizing their activities, securing funding for sports activities [17]. Similarly, work outside the education sector requires the graduate of physical education to have leader's skills, to present an attractive offer of sports and recreational activities, and its promotion [18]. Here it is necessary to know both the techniques of direct contact with customer services as well as knowledge necessary to the functioning in sports organizations and in local governments at various levels [19].

Implementing the idea of two-stage studies to ensure greater flexibility, high quality education, and better adaptation to the needs of the graduate competence to the job market is difficult in a situation of mass education [6, 16]. The studies showed that at the undergraduate degree studies the diploma is most important, essentially treated as a "pass" to the graduate studies, and less the acquired knowledge and skills. Moreover, the significant differentiation in the level of preparation of candidates, with both low expectations of some respondents to the general competencies such as: foreign languages, ICT, and the managerial preparation, and even lower levels of knowledge and skills acquired in this area may pose a threat to the quality of educational services measured by specific standards. This is particularly important precisely in the case of teacher education, where sound preparation for their profession seems necessary. In environmental debates, there are views that in the case of pedagogical studies with concern to the development of discipline and protection of the profession, teacher training should be conducted on a single master's degree, according to the model of education such as that of physicians [20].

The supporters of multi-stage education system emphasize that successful implementation of Bologna postulates, however, requires more effort and work put in by the student, as well as larger, individual commitment of academic staff. Furthermore, in accordance with the principles of the Bologna, the system of study needs to ensure adequate infrastructure of universities, mainly to improve the availability of better equipment and libraries and reading rooms (with computers, internet access). In case of failure to satisfy these basic requirements, the implementation of authors' expectations of the reform to improve the quality of education seems to be unrealistic.

Improving solutions for training of personnel for physical education requires further research and analysis e.g. in terms of public perception and evaluation of the twostage model of study. The gathered information may in fact be the basis for the comparative analysis of the effects of undergraduate and second degree studies, and evaluation 
of the results of one- and two-stage studies. In this context it seems relevant to have information about some other universities of the same educational profile.

Due to the sport "climate" of the academy of physical education and universally declared "input" interest of the subjects in the studied area, it seems relevant to undertake a broader study, explaining the reasons for the under-rated by students of both universities opportunities to develop their sporting careers. Significant would be finding an answer to the following question: does the implemented program of study and the related schedule occupy the students so much that they have not enough time and desire to implement an interest in sports, or they lack conditions for stimulating activities in this direction? The need for a closer look at existing programs of study also stems from the fact of their very critical assessment made by the representatives of both universities.

\section{Conclusions}

1. Taking undergraduate degree in physical education, subjects counted mainly on gaining knowledge and skills for further education, as well as professional competence.

2. The respondents most positively evaluated the process of education and the effects of physical education studies.

3. Most respondents considered undergraduate studies as a transitional stage for further education in the second degree studies.

\section{Acknowledgements}

The work has been prepared under the research project of the Faculty of Physical Education and Sport in Biała Podlaska, The Josef Piłsudski University of Physical Education in Warsaw - BW.III/29 - financed by the Ministry of Science and Higher Education.

\section{Literature}

1. Kraśniewski, A. (2004). The Bologna Process: where is the European Higher Education Heading? Warszawa: MEN. [in Polish]

2. Kozioł, L. (2001). System quality assurance in personnel training in the field of tourism and recreation. Zeszyty Naukowe AWF Kraków 81, 29-40. [in Polish]

3. Charlier, J., Charlier E. \& Croché S. (2007). The Bologna Process: The outcome of competition between Europe and the United States and a stimulus to this competition. European Education 39(4), 10-26.

4. Gvaramadze, I. (2008). From quality assurance to quality enhancement in the European Higher Education Area. Eur. J. Educ. 43(4), 443-455.

5. Kehm, B. (2010). Quality in European Higher Education: The influence of the Bologna Process. Change 42(3), 40-46.

6. Wójcicka, M. (2009). Changes in higher education with the Bologna process in the background. Przeglad Socjologiczny 3, 9-30. [in Polish]

7. Chełmecki, B. (2007). Training of personnel for the purpose of physical education from the perspective of the Bologna process. In J. Nowocień (Ed.), Socio-Educational view of contemporary sport and olympism. Patriotic Education through sport (pp. 180-185). Warszawa: PAOL, Fundacja Centrum Edukacji Olimpijskiej. [in Polish]

8. Oczachowska, A. (2006). Reasons for selection of the school of economics by the students. In G. Nowaczyk \& P. Lisiecki (Eds.), Marketing management of higher education institution (pp. 165-173). Poznań: Wyd. Wyższej Szkoły Bankowej w Poznaniu. [in Polish]

9. Kobylarek, A. (2003). University courses vs. labour market demands of the transformation of society. Nauka i Szkolnictwo Wyższe 21(1), 40-62. [in Polish]

10. Maszczak, T. (2001). Training of physical education teachers in the context of educational change. In J. Ślężyński (Ed.), Effects of training and education in physical culture (pp. 9-14). Katowice: AWF Katowice. [in Polish]

11. Buchta, K. \& Lisicki T. (2008). Employment status of students of physical education academy. In T. Lisicki \& T. Frołowicz (Eds.), Physical education teacher vs. the education challenges (pp. 19-29). Gdańsk: AWFiS Gdańsk. [in Polish]

12. Buchta, K. (2010). Graduate of the university of physical education in the labor market - start to professional career. Pol. J. Sport Tourism 17(1), 46-51.

13. Jaworski, Z. (2002). The development of physical education and employment opportunities of graduates in education. Physical and Health Education. Wychowanie Fizyczne i Zdrowotne 5, 20-23. [in Polish]

14. Lisicki, T. (2003). Professional Fate of Graduates of the Academy of Physical Education and Sport in Gdansk. Gdańsk: AWFiS Gdańsk. [in Polish]

15. Cieśliński, R. (2009). University education quality system - assumptions vs. practice in the context of the Bologna Process. Pol. J. Sport Tourism 16(3), 135-142.

16. Chmielecka, E. (2005). Two stages and directional structure of studies in Poland. How to loosen the corset? In J. 
Dietl \& Z. Sapijaszka (Eds.), Dilemmas of two-stage studies (pp. 57-74). Łódź: Fundacja Edukacyjna Przedsiębiorczości. [in Polish]

17. Umiastowska, D. (2009). Physical education teacher of the XXI century - the realities and expectations. Rozprawy Naukowe AWF we Wroctawiu 28, 228-232. [in Polish]

18. Osiński, W. (2001). Physical education teacher and his education vs. the challenges of the XXI century. Wychowanie Fizyczne i Zdrowotne 12, 19-23. [in Polish]
19. Ważny, Z. (2002). Personnel training and the requirements of modern sport. Sport Wyczynowy 11-12, 85-93. [in Polish]

20. Paśko, J. (2008). Training for fun or for needs. In B. Sitarska, R. Droba \& K. Jankowski (Eds.), Educational dilemmas of modern man and the quality of teaching in higher education institution (pp. 293-297). Siedlce: Wydawnictwo Akademii Podlaskiej. [in Polish]

Submitted: December 7, 2010

Accepted: February 1, 2011 